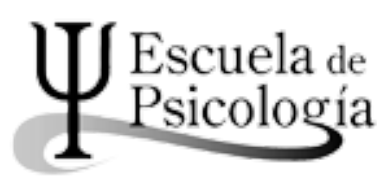

Wímblu, Rev. estudiantes Esc. de psicología, Univ. de Costa Rica. 12 (2): 43-65, 2017 / ISSN: 1659-2107

\title{
Cine Experimental y Documental Personal: Directores y Directoras que resignifican su yo a través del Cine
}

Experimental film and Personal Documentary: Directors who resignify their self through the Cinema

\author{
Darwin Yaney Mendoza*
}

Resumen: Este texto analiza la obra de seis artistas que replantean la percepción de sí mismos, a través de estrategias desarrolladas en su obra personal. Así mismo procura abrir un espacio de diálogo que conduzca a una más concreta investigación sobre el "yo" frente al cine, como aparato útil que, a manera de espejo, puede reflejarnos y mostrarnos detalles de la complejidad de nuestro "yo" y así comprendernos mejor.

Palabras clave: Cine autobiográfico, Exploración del yo, Cine Experimental, Documental Personal.

Abstract: This article explores the work of six artists who, through their personal approach to film, reshape the perception of themselves. Meanwhile, this text aims to open a dialogue that may drive us to a more concrete research about the Ego and the use of film, as aparattus to reflect details on the complexity of this Ego and, in such way, understand ourselves better.

Key Words: Autobiographical Film, Ego, Experimental Film, Personal Documentary.

Universidad de Ohio. Máster en Cine. Estados Unidos.

Correo electrónico: darwin-mendoza.mendoza@fulbrightmail.org

Recepción: 28/3/2017 Aceptación: 20/8/2017 
Este texto, dentro de la arena del análisis cinematográfico, pretende encauzar algunos caminos que conduzcan a una posible investigación psicológica sobre el yo. El cine autobiográfico se nos presenta como un extenso laboratorio clínico para poder encontrar, como cineastas, qué de extraordinario hay en nuestros rincones más mundanos, y como espectadores/investigadores, descubrir destellos de comportamientos y reacciones que nos ayuden a ir explorando, cada vez más ampliamente, una teoría psicológica del ser.

El siguiente análisis del cine como mecanismo terapéutico del (la) realizador(a), es solo el comienzo de un posible desarrollo mayor por mi parte, sobre las necesidades y los atrevimientos que como autoras(es) enfrentamos al explorar a través del cine, problemáticas humanas relevantes desde las vivencias y sufrimientos propios.

El cine en general, y el de ficción en particular, está copado de películas autorreferenciales que nos hablarían de estrategias de re-significación del yo y su proyección al mundo, basta con tomar como ejemplo el film recientemente ganador del Oscar a mejor película: "Moonlight" (2016). En este documento dejaré a un lado la exploración de la narrativa en ficción de tinte personal, con ello lamentablemente se queda fuera también la suculenta filmografía del maestro Alejandro Jorodowski.

Los márgenes principales de esta investigación, aun enfocándola y reduciéndola al cine de no ficción, resultan vastos e intrincados. Por ello, la selección de los ejemplos a analizar ha sido por descarte, una tarea de tamiz, dejo también de lado el sector más comercial o el main stream del cine de no ficción y con ello grandes nombres del documental contemporáneo como Michael Moore y Morgan Spurlock; sin embargo, en un análisis más extenso serán protagonistas indiscutibles. Dejo también aparte, otras geografías que en lo personal me interesan mucho en este campo del cine personal como la europea (Chris Marker), la rusa (Kossakovsky) y regiones orientales como Japón (Shinsuke Ogawa) y Taiwán (Lee Ching-Hui).

Otro de los nombres cruciales en este campo que se queda fuera de momento es Werner Herzog, de quien podría discursar en términos de cine autobiográfico documental y de ficción, analizando casi toda su filmografía esencial, aún teniendo solo un título en el que se atreve a mencionarse como personaje principal de su narración: "Mi enemigo íntimo", Herzog es protagonista y sujeto de estudio en casi todos los personajes principales que retrata, así podemos encontrar los márgenes de la locura del mismo director en nombres como Aguirre, Fistcarraldo, Hombre, Nosferatu y la lista irá creciendo, pasando por pobladores que se niegan a evacuar y enfrentan la posible muerte, monjes que trasgreden el caos mediante la contemplación, artistas de la era paleolítica, deportistas desafiantes y hasta un soñador narcisista que se unió espiritualmente a una manada de osos pardos, todos ellos personajes extremos y de allí la característica del cine de este excéntrico genio alemán. Es muy curioso que el mismo Herzog ha declarado en numerosas ocasiones que él no quiere entender qué lo persigue y perturba, que él no está interesado en la auto-exploración, sin embargo la auto-exploración es una constante en sus películas, las cuales que llevo varios años investigando al mismo tiempo que sigo leyendo rincones de su biografía que dan sentido a tan fascinante obra fílmica.

Con ello, la exploración se sitúa en la geografía americana, en la escena de producción y distribución independiente y proviene principalmente de dos grandes vertientes, el cine experimental y el documental personal.

Definiendo los parámetros de este estudio, analizaré solo una obra de cada uno de los seis autores y autoras que he seleccionado y dentro de estos me incluyo como documentalista, haciendo con ese último análisis, al final de este artículo, un esbozo de ejercicio meta-explorativo. Los cinco autores principales de este estudio son: Maya Deren, Hollis Frampton, Pilar Leciñena, Jonathan Couette y Marcela Zamora. Con la obra de estos autores procuro abrir una ventana que invite a la investigación del yo, estableciendo coordenadas para explorarlo.

Ubicándonos en la corriente del Cine Experimental, brindaré un punto de vista personal sobre: "Meshes of the afternoon" de Maya Deren; "Nostalgia" de Hollis Frampton y "Leticia de Oyuela se escribe siempre con L de Libertad" de Pilar Leciñena. En la rama del documental personal, discursaré sobre "Tarnation" de Jonathan Couette; "Los ofendidos" de Marcela Zamora y cierro con una reflexión sobre el documental "La orilla del río" de mi autoría.

$Y$ es que el cine experimental y el cine documental desde los comienzos mismos de la cinematografía han estado íntimamente unidos, es solo necesario citar como ejemplo concluyente, el magistral filme: "El hombre con la cámara de cine" (1923) del gran teórico y director Dziga Vertov, deudor de una larga lista de influencias maestras del cine como los hermanos Lumière, el gran George Méliès, y él mismo, perteneciente a una de las más poderosas generaciones de creadores de cine en su tiempo: DW Griffit, First Lang, Lotte Reininger, Walter Rutman, Joris Ivens, Robert Wiene, Germain Dulac y su compatriota Sergei Einsestein, entre otros y otras. Todos estos artistas ejercieron una gran influencia en cine por venir y esto tuvo un gran impacto y fruto en los Estados Unidos, donde el cine se amplificó. La escena experimental norteamericana es una de las más impresionantes carteleras de películas aún por descubrir, teniendo su origen como contra propuesta a la cartelera dominante, junto esfuerzos con el cine underground y lograron establecer las bases de un cine alternativo y con mucha fuerza. Dentro de sus fundadores, mencionamos siempre a figuras muy reconocidas como: Norman Mclaren, Kennet Anger, Jonas Mekas y Maya Deren.

Debido a la naturaleza y propósitos de estos análisis, debo advertir una alerta de spoiler. Lo mejor sería ya haber visto las filmografías|objeto de estudio de las siguientes líneas, para poder contrastar puntos de vista; no obstante, y de 
no ser así, que sirvan estos análisis como un contexto muy subjetivo, previo al visionado de estos seis filmes.

\section{Maya Deren: Coordenadas creativas de su propia identidad}

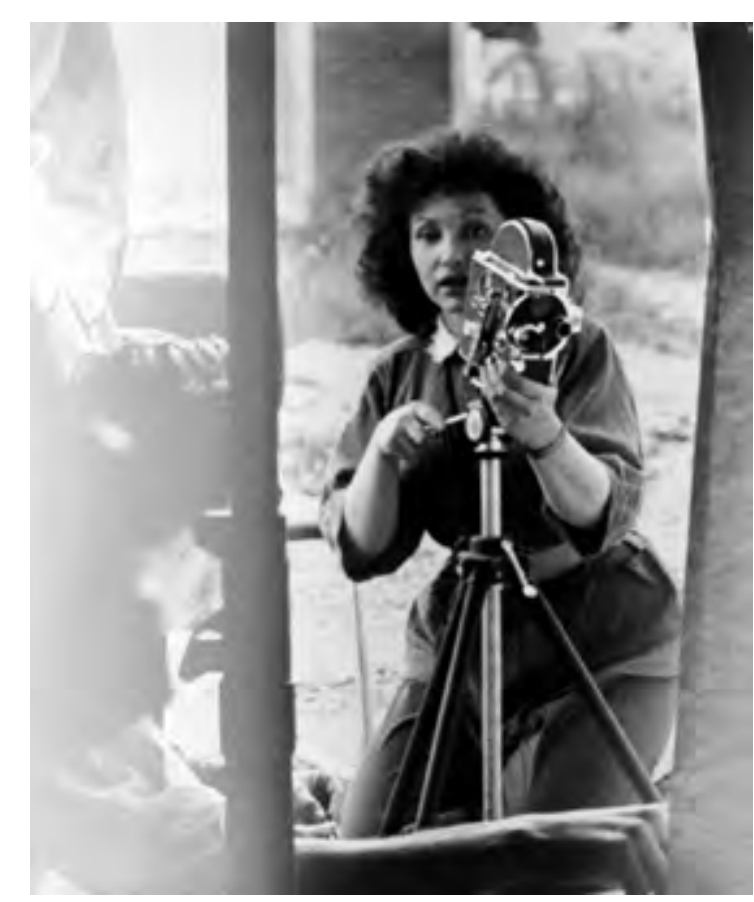

Figura 1. Maya Deren

Una propuesta de cine evidentemente personal-psicológico, la cámara se convierte en la voz y la mirada misma de Deren (FIgura 1). Esto podemos aplicarlo a todo su trabajo fílmico. Este primer análisis es muy relevante para mi exploración del ser, puesto que estamos ante la hija de un psicoanalista que toma el camino del arte para su expresión.

Centrándonos en "Meshes of the afternoon", primer trabajo fílmico de Deren, elaborado en el año 1943, justo el mismo año que muere su padre, percibimos a través de un acercamiento al lenguaje visual, la presencia cuestionadora de su autora.

Por ello, para elevarnos y visualizar mejor las pistas psicológicas del discurso, estructuré una plataforma sólida identificando los elementos técnicos y físicos de medio cinematográfico y la forma han sido usados por su autora en esta película.

Un temprana declaración nos indica que el film fue "hecho en Hollywood", esto se vuelve relevante primero porque es cierto, fue grabado en esta área de Los Ángeles $y$, porque en términos de la industria del cine que nos evoca
Hollywood como nombre, Hammid acreditado también como director de esta película, trabajaba ya para este entonces en la industria y es quien proporcionó los medios y la experiencia técnica para realizarlo. Por otro lado, es importante en este análisis, porque evidencia un tono irónico, pues la película se convierte en una contrapropuesta a la mirada objetual que más para este entonces Hollywood imperaba hacia la mujer.

Años más tarde, Laura Mulvey (1999) con su bien conocido ensayo "Visual Pleasure and Narrative Cinema" aplicando una teoría psicoanalítica, explora como la narrativa tradicional de Hollywood representa la diferencia de género imponiendo una mirada masculina escopofílica activa sobre la mujer, quien queda reducida a objeto pasivo de esa mirada. Mulvey en este ensayo, hace también una declaratoria y urge al desarrollo de un cine alternativo que valore en iguales condiciones espectatoriales el placer que le han sido negado a la mirada femenina. Esta película discurre alrededor de ese prisma mientras explora a la vez, cuestionamientos de identidad.

Esta es, probablemente una de las piezas audiovisuales de las cuales se puede escribir múltiples interpretaciones. "Meshes...", desde un punto de vista del medio cinematográfico como protagonista, presenta una evolución que se mueve en la dualidad propia del aparatus fílmico, compartida con la mística del sueño, por un lado su capacidad de darnos la sensación de vivir la experiencia real, y por otro, las infinitas posibilidades de alterar esa realidad.

Comienza con una imagen fotografiada en exterior muy apegada a lo "real", aunque muy poética y simbólica. Una acción de marcar el camino para comenzar un recorrido, este punto de salida es un objeto/símbolo: una flor. Toda su carga semántica sutilmente nos prepara el contexto en el que deambulará nuestra mirada. Es una película muda (no silente), y para enfatizar esta negación al diálogo verbal, Deren lo evidencia a través de dos elementos sonoros silenciados visualmente: el teléfono y el fonógrafo.

El otro elemento propio del medio que fácilmente identificamos y que ayuda para sentirnos seguros al seguir indagando arremetimientos simbólicos de la narrativa es la capacidad del cine de alterar el tiempo y propiciar la repetición de hechos ocurridos.

Una vez que vamos siendo conscientes como espectadores, que estamos ante un discurso cinematográfico, podemos dejarnos llevar en la poesía sin dejar de ser conscientes de que nuestro papel puede ser por un lado, involucrándonos con el personaje o simplemente quedarnos estáticos como observadores.

Este mediometraje se desarrolla frente a nuestros ojos como un ejercicio de autorreflexión por parte de su autora. Deren cuestiona su identidad y sus miedos desdoblándose y multiplicándose para poder ser al mismo tiempo sujeto activo y sujeto pasivo de su propia mirada, antes de ser objeto y sujeto de la mirada de un otro. La locación principal (casa) se presenta como un anagrama y 
todos los elementos que la componen le permiten a la autora moverse y ubicarse desde innumerables puntos de vista para explorase. Estos elementos simbólicos la ubican dentro y fuera (la llave), arriba y abajo (la escalera), cerca y lejos (la ventana), sola y acompañada consigo misma (la mesa); así como, frente a frente (el espejo) y, finalmente, toda esta exploración de sí misma la lleva a una última dualidad como persona: ser atacante y a la vez ser víctima.

Esta reseña, es solo un acercamiento a los logros argumentales propuestos por Deren con los que nos encontraremos en la película; sin embargo, la calidad que hace de esta película una obra maestra, aun impresionantemente siendo una ópera prima, es la forma de utilizar los recursos cinematográficos, para de una manera fluida, hacernos llegar claves de esas sensaciones que la protagonista sufre en cada momento y la ubicación desde donde ella mira. Por ejemplo, el recurso práctico de la desaparición y aparición de objetos, propio del mejor cine de George Méliès, nos permite justificar la desorientación que sufre el personaje principal, de la misma manera que lo hace el movimiento -cámara en mano- potenciando su interpretación, a través de la oscilación coreográfica de su cuerpo. La utilización libre de una gramática fotográfica en términos de encuadre e iluminación, el ritmo y la estructura circular casi espiral de la edición, nos envuelve progresivamente en una sensación confusa propia de lo onírico, estado mental transitorio del que no sabemos cómo saldrá nuestra protagonista.

Tres años después de completar esta película Maya Deren, desarrolló una teoría que llamó: "Un anagrama de Ideas en Arte, Forma y Cine" donde establece que la finalidad de esta película, como de toda obra de arte, es crear una experiencia, en este caso fue "crear una realidad semi-psicológica".

Maya Deren es considerada una de las precursoras del Nuevo cine Americano y ciertamente, es una de las indiscutibles protagonistas de la escena experimental norteamericana. Interiorizarnos en su primer film, es solo una invitación a buscar su filmografía; en las cuales, sigue igual que en esta película, proponiendo el cine como una amalgama de conceptos y técnicas que se enriquecen de las diferentes disciplinas artísticas, es necesario notar que antes de comenzar su carrera como directora y productora de cine ya incursionaba las artes a través de la danza y la poesía habiéndose formado entre otras facetas como bailarina coreógrafa y especialista en literatura y más específicamente en poesía simbolista. Esta formación académica unida a una búsqueda constante por definir una identidad personal, debido a su recorrido vital desde su natal Ucrania, pasando por Estados Unidos y terminado en lugares tan diferentes de éstos como Haití y Japón $y$, a cuestionamientos en términos de género desde antes de nacer, hacen que su cuerpo de trabajos artísticos mantengan un vínculo estrechamente personal con lo estético, llegando a verla como persona inseparable del medio. Esto la llevo a incursionar también en la teoría como medio para poder analizar y analizarse dentro de toda su propuesta cinematográfica.
Hollis Frampton: El desafío de la noción del yo a través del cine

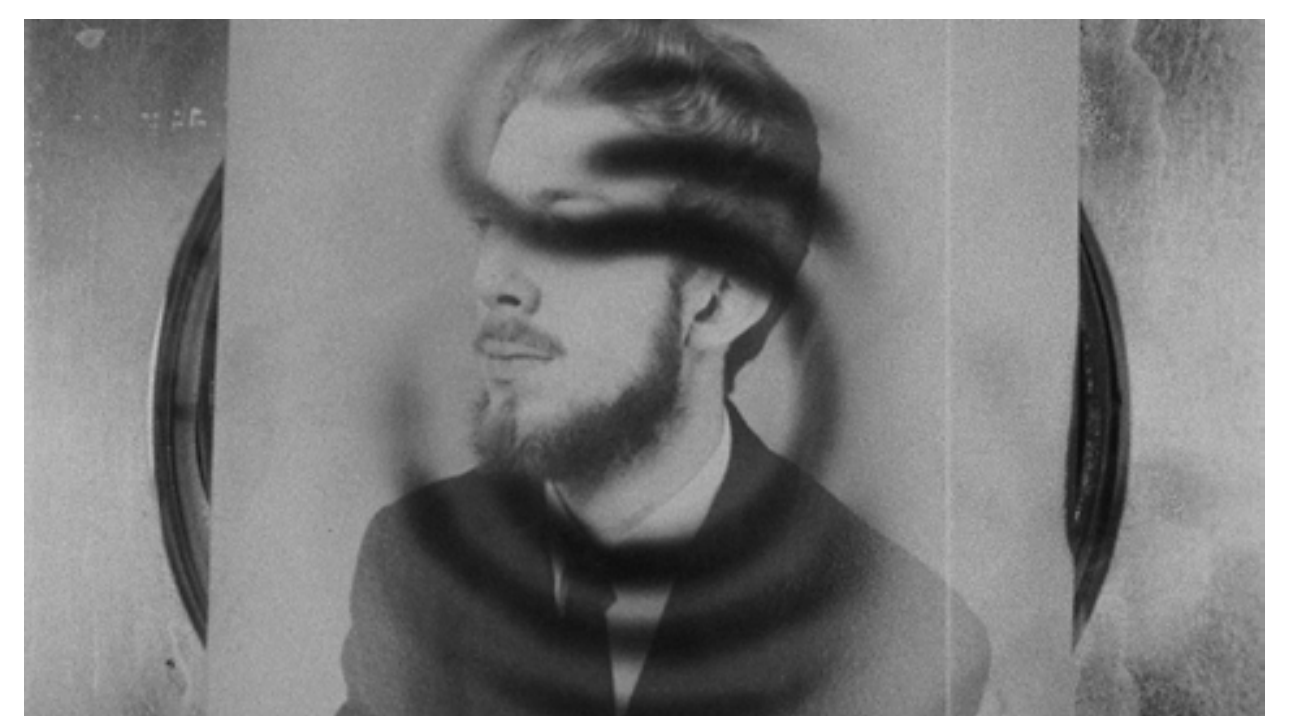

Figura 2. Hollis Frampton

Para comprender esta premisa, comenzaré por describir el comienzo de su película "Nostalgia" 1971 (Figura 2).

(sonido de los engranajes de la cámara de cine)

Una voz directamente a un micrófono.

(Voz en off)

- ¿Está todo Bien?

- Sí todo bien...

- Estas son recolecciones de docenas de fotografías que hice hace varios años atrás...

- ¿El sonido está bien?

- Sí perfecto, está bien.

(Pausa)

(Voz en off)

-Esta es la primer fotografía que hice con el claro propósito de hacer arte.

Me había comprado una cámara para navidad en 1958. Un día a comienzos de enero del 59, fotografié varios dibujos de Carl André, con quien compartí un apartamento pequeño en la calle Mulberry. Quedaba una foto y le sugerí a Carl que se sentara o se agachara para un retrato. El insistió que la fotografia debería contener un pequeño y lindó marco que le había regalado hace como un año una chica llamada North. Como 
El marquito apareció en otra fotografía fechada en marzo de 1963, pero no es el de tolerar su sincopatía por un tiempo.

(pequeña pausa)

Carl André es doce años mayor y más activo de lo que era entonces. En estos días le veo menos de lo que me gustaría, pero también hay personas que veo más de lo que importaría verlas. Odie esta fotografía por varios años. Pero no me veo destruyendo un negativo tan incriminatorio.

(en imagen, vemos una fotografía impresa que casi llena todo el cuadro de la panun espacio de trabajo donde pueden estar los elementos de los cuales nos está hablando la voz en off. De repente la fotografía comienza a quemarse hasta quedar reducida a cenizas. Esta acción da paso a un corte limpio en edición donde quedar otra fotografía ante nuestros ojos, en la imagen ahora vemos a un joven detrás de un pequeño marco interactuando con un metrónomo y comienza la voz en off a describírnosla)

(Voz en off)

-hice esta fotografía el 11 de marzo de 1959. El rostro que aparece es mío, o más claramente, era mío. Como pueden ver yo estaba muy contento conmigo mismo cumpleaños número $23 .$.

Fin del ejemplo.

Así continua describiendo con detenimiento no solo lo visual en la foto sino también detalles del contexto en que fue tomada o los elementos personales de sí mismo en ese momento.

¿Qué hace de Nostalgia una obra maestra del cine y para el cine?

Que dentro de su aparente simpleza técnica y visual, engloba una trama muy elaborada y cargada de contenido psicológico y de auto representación como ningún otro film ha podido lograr.

Para comenzar, técnicamente es una película que mediante un proceso de metalenguaje habla de sí misma, de la misma manera que su autor Hollis Frampton habla de sí mismo. Si en el trabajo analizado de Maya Deren, encontramos una película que sirve de vehículo de auto exploración del yo, en esta película encontramos un marco perfecto para desafiar la noción del yo por parte de su autor.

¿Cuáles son las claves para que el espectador dude de que lo que nos esté contando Frampton en primera persona es representación de la realidad o recreación de la realidad?

Primero, y esto es imperceptible para nosotros, la mayoría de los espectadores que no conocimos personalmente a Frampton, cuando está probando el funcionamiento del micrófono necesita estar seguro que el audio está funcionando correctamente, esto a la larga es una advertencia al espectador de que el audio es crucial en esta película, no solo porque será enteramente audio descriptiva, sino porque una de las trampas es que las descripciones de las fotografías personales de Frampton está en completa desincronización con la imagen, de tal manera que el director juega sucio con nosotros porque no describe una fotografía que no veremos sino en un futuro casi inmediato, pero junto a la descripción de otra fotografía que vendrá más tarde en el futuro, de tal manera que el espectador no puede concentrar su atención en lo que ocurre en ese momento ante sus ojos, porque está siendo sugestionado con otra información muy diferente.

Segundo, la voz que realmente escuchamos no es del propio director sino de su amigo y colega Michael Snow, otro gran cineasta experimental que por la complicidad con Frampton, puede albergar momentáneamente el yo de Frampton en sí mismo.

Esta compleja plataforma que nos ha creado el director para desnudarse frente a nosotros, sin ser él mismo, es simplemente fascinante cuando uno como espectador ha empezado a descifrar el juego cinematográfico que nos plantea "Nostalgia".

Desde otra perspectiva, si seguimos las líneas verbales que nos entrega Frampton desde un principio, encontramos los elementos conceptuales clave con los que él jugará, el protagonismo del metrónomo no es solo visual sino conceptual, esto desde ya, nos advierte que el ritmo en esta película oscilará entre la pulsación repetitiva y estos cortes abruptos de sincronía.

Desde un principio la narración nos dice claramente que se trata de un film muy personal, nos sitúa en un momento específico en la vida de este autor cuando implica que es el comienzo de su carrera como artista (su yo artístico), un comienzo que ha sido posible gracias a sí mismo, al regalarse su cámara para navidad. Esta relación entre el autor y el medio da paso a implicaciones mayores como el odio en algunos momentos y los sentimientos de culpa por destruir su propio trabajo; y es que aunque nos sugiere que los negativos han quedado a salvo, vemos como deliberadamente está quemando cada fotografía que nos presenta. Esta acción que puede verse como muy agresiva y violenta para consigo mismo, nos involucra como testigos de un acto de auto destrucción.

Además, la descripción nos da detalles íntimos de esta persona al describirnos particularidades como que su apartamento era pequeño y compartido con el artista Carl André, a quien usa también para situarnos en términos de tiempo y, a su vez, darnos pistas de su personalidad cuando nos describe que hay gente que suele ver mucho y no le importaría dejar de ver, por ejemplo. Es una película que aun dirigiendo información directa hacia nosotros, ya nos ha condicionado para no prestar toda la atención a esta información entregada sino a buscar el subtexto en todo esto para encontrar la información sugerida o implícita en cada detalle de la película. Volviendo al tema de la auto destrucción, si reflexionamos en el medio que 
él está usando para documentar la destrucción de una fotografía, es totalmente irónico, puesto que en realidad la está multiplicando e inmortalizando a través del mismo medio fotográfico, recordemos que la cinta de cine no es más que una sucesión de fotografías fijas puestas en secuencia para dar la falsa sensación de movimiento. En tanto, el acto de destrucción pensándolo fragmentado deja de existir y aun si tomamos como característica propia del cine la secuencialidad y el tiempo, no olvidemos que el cine tiene la característica casi mágica de retroceder el tiempo secuencial por tanto, si rebobinamos la película vuelve a comenzar nuevamente y si visualizamos esta acción de retroceso proyectado, lo que tendremos es en vez de un acto de muerte, es un acto de volver a la vida de las fotografías ante nuestros ojos.

Una gran película como esta no puede adolecer de un final enigmático y conclusivo. Evitaré detallar la narración de la última fotografía que deberíamos ver en esta secuencia, rescataré en vez, algunos elementos conceptuales de esta descripción. Frampton se refiere a una fotografía que tomó en un exterior y fue interrumpida por un automóvil, sin embargo en el proceso de revelado descubrió un pequeñísimo detalle que decidió ampliar y que le sacudió. El potencial desarrollado de la cámara de fotos a diferencia de nuestro ojo desnudo, radica también en poder capturar y mantener detalles tan minúsculos llenos de información. (esto es el principio fundamental de la película "Blow up" de Michaelangelo Antonioni) para nosotros los cinéfilos empedernidos, esta descripción de Hollis Frampton es una referencia directa a esta película de 1966 y a Julio Cortazar, año en el que Frampton indica que tomo esta sugerente fotografía y que, lo que él cree haber grabado en este fragmento de imagen lo llena de miedo, a tal extremo que nunca debería atreverse a hacer alguna otra fotografía... termina diciéndonos claramente..

\section{iAquí está!}

iMírenlo!

¿Ven lo que yo veo?

\section{Pilar Leciñena: Cine-Arte contemporáneo y un acto de liberación} trascendental

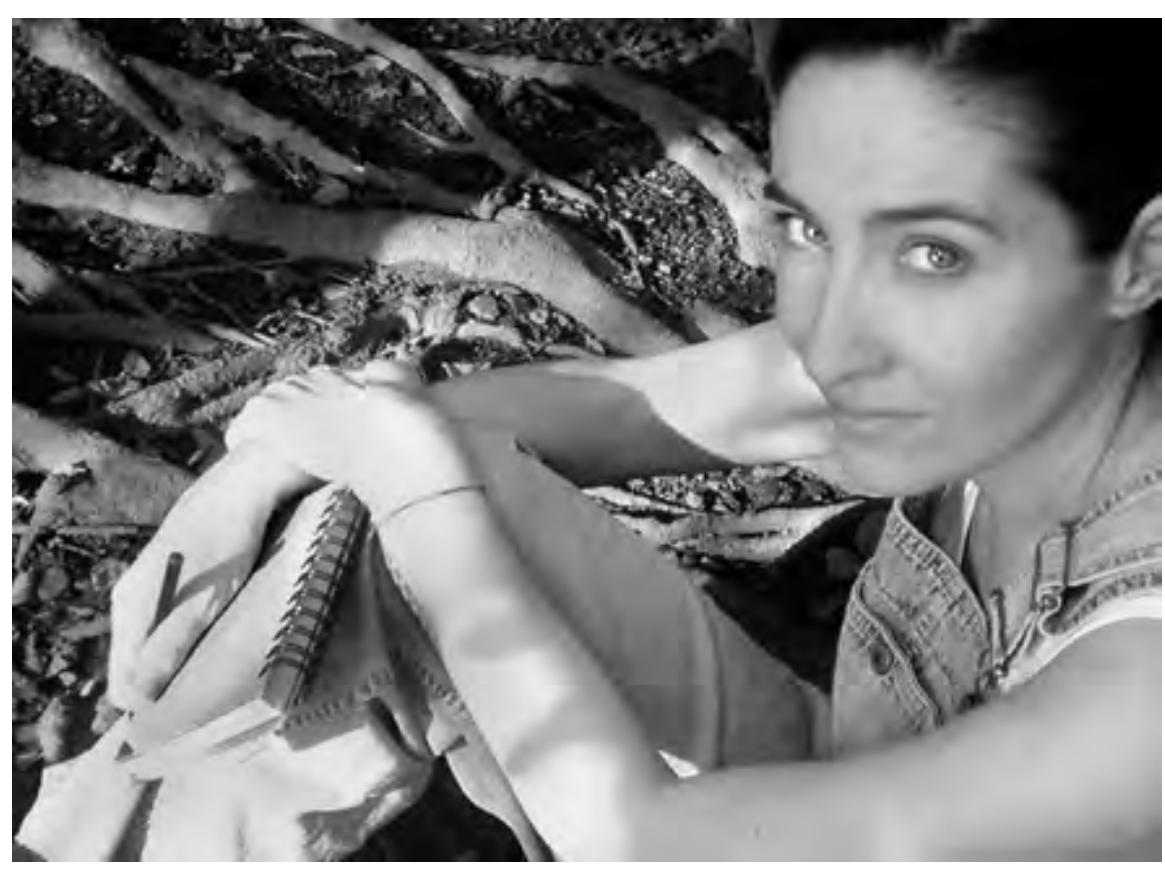

Figura 3. Pilar Lenciñena

Con la apertura de las prácticas artísticas contemporáneas a nuevos territorios más transdisciplinarios, el cine se ha beneficiado de enriquecer su espectro. E videoarte, el performance documentado audiovisualmente, el cine ensayo y el videopoema como prácticas del cine experimental, han ampliado grandemente las inquietudes de percepción y las desliga, cada vez a más distancia, de las estrategias tradicionales de nuestra conexión con la realidad. Las obras de arte en el presente, se posicionan con discursos cada vez más mentales, sensoriales y afectivos como complemento de su cuerpo textual y técnico/estético. A la vez, en la actualidad, el arte contemporáneo sufre de una masificación y adolece, muchas veces, de singularidad, esto puede verse en la mayoría del arte contemporáneo "conceptual" que es cada vez más objeto-dependiente. En ello, discursa desde un punto de vista filosófico, quien pronosticase en su momento el fin del arte, Arthur C. Danto en su ensayo "Transfiguration of the commonplace." En este texto, publicado en los albores de nuestra era artística presente, Danto intenta aclarar una definición del arte respondiendo a los atributos y atribuciones del arte mismo, haciendo énfasis en la carga semántica que hace de una simple propuesta técnica, una propuesta relevantemente artística gracias a la característica de la significación. A esto agregaré que cuanto más personal el discurso que toma 
cuerpo en esa obra, más singular se muestra dicha obra de arte en esta prolífica era creativa. Aquí el aspecto psicológico aporta al filosófico, un territorio aún más amplio de exploración.

La obra artística de María Pilar Leciñena Monguilod (Figura 3), se caracteriza además de una alta estética, por su especial mística, sugerente e inspiradora, con discursos cargados de mucho simbolismo. Dentro de su más reciente obra, donde prevalecen mayormente temáticas sensibles como la atención a la niñez y la problemática de la migración, he seleccionado para esta disertación trabajos cuya entrega semántica surge de poéticas comunicaciones, muy personales e íntimas, que son motivadas -en esta etapa- por el dolor de la pérdida.

Extraordinarios trabajos que muy generosamente Pilar nos comparte. En este sentido, podemos mencionar la instalación "Vía Aérea" dedicada a sus padres (In memorian) en el contexto de la acertada exposición retrospectiva que hiciera de su obra en 2014, el Centro de Arte y Cultura de UNAH, o la escultura-poema homenaje a su amigo, el brillante escritor Oscar Acosta (QDDG). En la pieza objeto de este análisis: "Leticia de Oyuela se escribe siempre con L de Libertad" 2008, Pilar dirige una comunicación emotiva a su íntima amiga, la gran intelectual hondureña Doña Leticia Silva de Oyuela, tras su fallecimiento y a propósito de su sensible pérdida.

Es necesario destacar, para quienes no conocieron a Doña Leti, como cariñosamente se le trataba, que, más allá de ser historiadora y literata, fue una constructora de memoria en Honduras, usando la literatura como herramienta para definir la identidad. Su extenso y crucial trabajo intelectual vivía constantemente amenazado y aprisionado en una limitada movilidad física, pero ella, a través de su trabajo intelectual, luchó y venció siempre esta limitante. En el 2003, el escritor Nery Alexis Gaitán le pregunta en una entrevista cual será su siguiente proyecto, ella responde que ya tiene problemas más severos de la vista y de movilidad, que la vida cada día se le complica más. Dos años más tarde, gracias a su lucha incansable, publica en colaboración con Pilar Leciñena el magnífico libro "Ángeles Rebeldes" y tres años después estas dos creadoras colaboran nuevamente en su último libro publicado en vida "El naif en Honduras". Fallece en su natal Tegucigalpa en el 2008 y, como bien dijo nuestro escritor amigo Julio Escoto: se nos fue "la última heroína" de Honduras.

En el videopoema de Pilar, encontramos una reflexión del yo siendo testigo de una liberación y aplicando a sí mismo un acto de liberación a través del recurso de la cámara. "Leticia de Oyuela se escribe siempre con L de Libertad" es un íntimo y precioso poema audiovisual que tiene implícito un receptor directo, quien da título a esta obra, nosotros como espectadores de esa comunicación muy personal, somos únicamente testigos a la vez, de un acto doble de liberación. Esta película no está dirigida a nosotros, está dirigida Doña Leti y en última instancia a Pilar misma.
En términos técnicos, a diferencia de Deren, Pilar no se retrata físicamente en la pantalla, y a diferencia de Frampton, sí expone su voz propia en la narración y no advierte presencia del espectador, sino que maneja la verbalidad en un íntimo diálogo interno que en el momento de la liberación se convierte en un sutil soliloquio.

En el caso de "Leticia de Oyuela se escribe..." lo normalmente -subjetivo-, propio del cine y más evidente en el cine personal, lo elevo desde una perspectiva sociológica siguiendo a Alfred Schütz, a una implicación "intersubjetiva", porque así podremos acercarnos mejor a este fenómeno de una vivencia compartida de liberación. La intersubjetividad según este autor está determinada por una conexión de sintonía hacia un "tú" que a diferencia de un "otro" es establecida en una tan cercana relación-nosotros. Este contexto explica o demarca la unión de la autora con su intercomunicadora Leticia, y el significado que da Pilar a la vivencia de liberación de Doña Leti con quien compartieron en complicidad ese proceso continuo de construcción en términos de identidad hondureña. Trayendo este exquisito videopoema al terreno indagador de la personalidad auto-explorada, completo tres muy buenos ejemplos que el cine experimental nos regala para ahondar en el análisis de las estrategias que cuestionan el yo y lo ponen en disposición para su re significación.

En el campo documental, el cine de no ficción contemporáneo ha acumulado una serie de trabajos tan originales, de tal manera, que se ha convertido en un perfecto medio para la exploración narrativa y el estudio teórico del comportamiento de la sociedad. Más allá de que la historia del cine aparece ligada a la documentación de hechos y eventos, el uso del cine -como medio para contar historias de ficción- es lo que ha creado en sí una industria, Actualmente hay un creciente interés, más por parte de los críticos de cine, promovido por innovaciones técnicas y conceptuales en la narrativa que dirigen la atención al cine documental. Paul Arthur en su artículo "Extreme Makeover: The Changing Face of the Documentary" reafirma que este interés creciente va ligado a la actual extrema realidad mediatizada que vivimos. Interesantemente, muchas de las propuestas más innovadoras y reaccionarias vienen retratando realidades internas, y en este sentido el documental personal nos ha dejado grandes títulos, muchos de ellos poco conocidos pero imprescindibles para su estudio psicológico y estético como son, sólo algunos ejemplos: "Silverlake life: a view from here" de Peter Friedman y Tom Joslin, "David Holzman's Diary" de Jim McBride, "The Ties that Bind" y "Sink or Swim" de Su Friedrich, "Acta general de Chile" de Miguel Littin, Tarnattion" de Jonathan Couette y "Los Ofendidos" de Marcela Zamora. 


\section{Jonathan Couette: El yo compartido, ubicado en mi y en el otro a la vez}

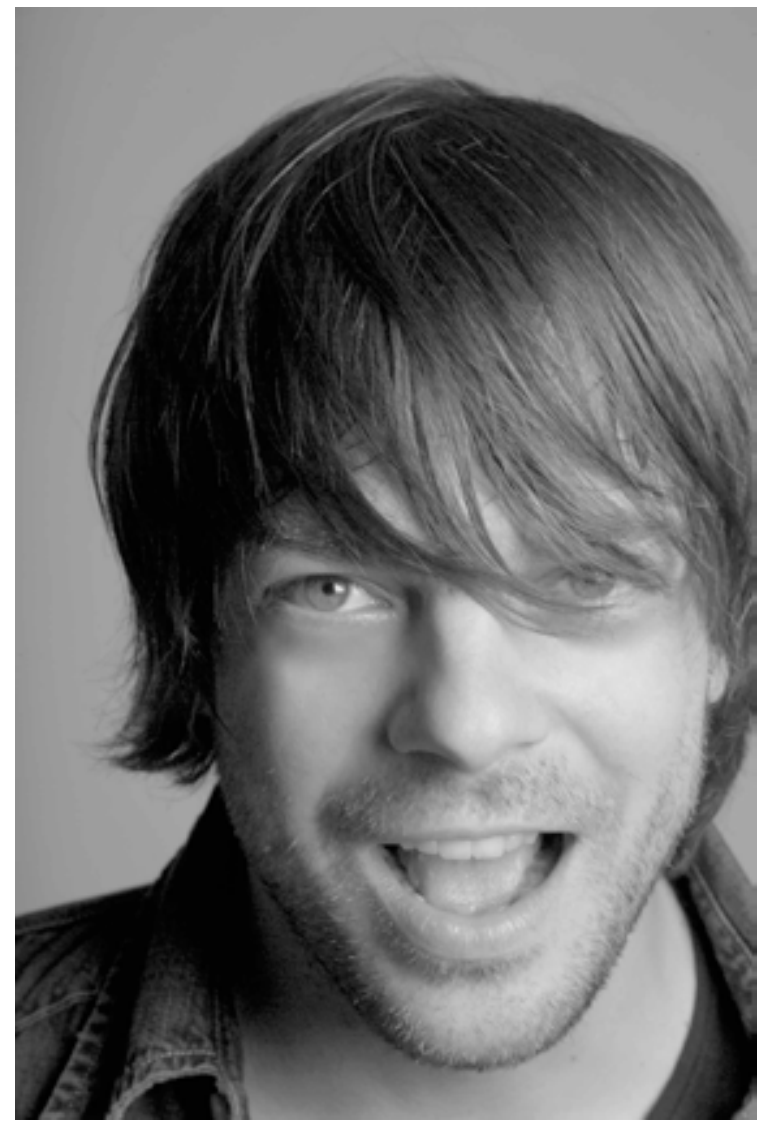

Figura 4. Jonathan Couette.

"Tarnattion" (2003), fué seguido por "Walk away Renee", un documental secuela que aborda eventos posteriores a la realización del primer trabajo documental, ambos ligados desde una perspectiva biográfica por parte de su autor, Jonathan Couette. Este análisis se centrará en "Tarnattion", un documental realizado con muy bajo presupuesto y con muy sencillos recursos técnicos, en comparación con la repercusión que adquirió.

Esta película en estructura es, por un lado el recuento biográfico de Renee le Blanc, madre de Jonathan, pero a la vez, intercalado es el recuento autobiográfico del mismo director, y esto responde desde mi punto de vista (consciente o no por parte de Jonathan) a un intento de unificación de su ser en ambas personas. El otro aspecto que los unifica es conductual desde un punto de vista legal, al intercalar la potestad jurídica el uno sobre el otro. Esto infiere una cuota de poder de uno sobre el otro, en el caso de Jonathan, su madre tuvo la potestad primero sobre él cuando era niño; la vida da muchas vueltas y de adulto, es él quien adquiere potestad sobre su madre debido al avanzado estado de desequilibrio mental de ella.

"Tarnattion" nos cuenta la relación de Jonathan con su madre y nos sumerge en un testimonio de vida (puesto en escena), que a su vez busca explicaciones y culpables de la situación de vida que ha llevado Renee y por consiguiente el mismo Jonathan. La otra relación fuerte que nos grafica este documental es la de Jonathan con el cine. El vínculo de Couette con el registro cinematográfico es muy fuerte. La cámara acompaña a Jonathan de manera personal y consciente, desde la temprana edad de 11 años, de donde surgen unas perturbadoras y reveladoras imágenes del conflicto de personalidad de este director en su edad adolescente (etapa crucial para la formación de la identidad), luego muy joven, es expuesto a la escena fílmica underground de la que él participó muy activamente, a través de sus películas, en gran medida personales o familiares y finalmente de adulto, actualmente trabajando como actor, determina realizar este documental del cual a continuación analizaré en algunos aspectos importantes.

Es un documental que habla del ser en diferentes etapas y circunstancias; cercanía, distanciamiento, separación, protección. Film que se puede volver polémico en términos de honestidad en el testimonio. Jonathan no manipula nuestro punto de vista como espectadores en el sentido que la narrativa tradicional lo hace, él toma la cámara como su terapeuta y la ubica más en relación con sigo mismo.

Si hablamos de honestidad, la parte central del metraje nos ofrece registros muy reveladores, cuando vemos el material de archivo de un Jonathan alrededor de los 10 a los 16 años, personificando y representando emociones y reacciones con una conciencia limitada del alcance de este poderoso medio (el cine). A esta edad, es notorio que del medio audiovisual (video) Jonathan solo le pide registrar sus comportamientos, esto es muy relevante puesto que frente a la cámara abandona completamente su yo para representar mujeres maltratadas. Hillary y Sharell y su imaginada tumultuosa relación en un círculo de violencia doméstica, graba también a sus abuelos y registra el mundo social que lo acoge. Es a esta edad que Jonathan habla consigo mismo, a través del video, sobre su identidad sexual y sus miedos.

La historia en este documental nos lleva a un Jonathan, no consciente de su propio ser y no capaz de comprender lo ajetreado de su mundo, que está fuertemente unido a su madre, esto potenciado por la falta de la figura paterna desde antes de nacer. Este proceso que pudo haberse desarrollado normalmente para el crecimiento del pequeño Jonathan, sufre un cambio drástico al separar a su madre de él y comenzar una procesión a través de diferentes entes que intentan sustituir ese vínculo que le proporcionaba su madre. Entre estos 
sustitutos están Foster parents (padres de acogida), sus abuelos, sus amigos y finalmente la cámara de video. Esta relación de unificación de este vínculo la vemos restablecerse en la actualidad cuando se han invertido los papeles, ya no es Renee quien puede decidir por Jonathan, sino es Jonathan adulto, quien tiene la facultad legal de decisión por Renee, debido a la gravedad del desequilibrio sufrido por ella.

En este momento del documental, y debido a esta circunstancia de control casi absoluto de Jonathan sobre el ser de Renee, ocurre una de las secuencias más reveladoras de la fragilidad del documental personal en términos de ética -lo ético como constructo social y en este caso, desde un punto de vista totalmente subjetivo de mi parte-, considero que Jonathan, al sostener la cámara dirigida a Renee por alrededor de 5 minutos y medio, en los cuales ella aparentemente inconsciente de su estado personal canta infantilmente un sinsentido alrededor de una calabaza, incurre en una falta de ética documental. Podría parecer insignificante, pues es parte de la labor del documentalista registrar este tipo de reacciones, mi cuestionamiento viene al editar y presentarnos el material, que tan necesario es para el espectador ver por un tan prolongado espacio de tiempo la inestabilidad de Renee. Me parece que Jonathan no es consciente que está grabando a un otro y no a sí mismo, hasta qué punto su estatus legal de protector le da la autorización de exponer estas reacciones y la condición de su madre por tanto tiempo como si se tratara de exponerse a sí mismo. Es evidente que esta secuencia le agrega mucho dramatismo a la película, ya que la secuencia precede a imágenes del director encarando a su abuelo y cuestionando la decisión de haberle aplicado choques eléctricos Renee de joven y acusando a esto, la actual condición mental de su madre. Por lo tanto en términos de ética, la cuestión es hasta qué punto puede, el documentalista, intensificar con estos recursos, los momentos dramáticos para lograr un mayor impacto. Fuera de eso, es sumamente relevante que el mismo Jonathan no se muestre consecuente con que, aunque psicológicamente su madre no es consciente de su yo en ese momento, él debe proteger su intimidad y no exponerla de esa manera tan prolongada.

Al final de la película, el Jonathan adulto habla directamente a cámara y conscientemente enfatiza esta circunstancia de sentir a su madre parte de sí ya no solo metafóricamente, sino en términos de significación más profunda. Sus palabras hacen ver ese miedo de seguir el mismo camino de su madre y terminar como ella, un indicio que él, en su camino de vida, se ha distanciado de su ser para sufrir y encontrarse a sí mismo en la personalidad y las circunstancias de su madre. Incluso a esta edad (31 años) se referencia en la persona de su madre pensándola en el pasado, a esa misma edad.

Así mismo nos dice, que no puede escapar de su madre, que ella vive dentro de él, que ella está dentro de su piel. Claro que esto no me parece del todo tan honesto siendo que es una puesta en escena frente a cámara, pero no deja de ser interesante que declare este tipo de cosas porque son pensamientos y aun en un nivel de razonamiento se evidencia esa fuerte atadura que une a esta madre con su hijo.

Desde un punto de vista formal, Couette parece muy interesado en que como espectadores veamos o sintamos algunas de las sensaciones-alucinaciones experimentadas por él o por su madre, esto lo grafica en la fragmentación y multiplicidad de la imagen o la distorsión cromática y lumínica aplicada al video. La imagen adquiere una presencia muy fluida y fuerte por el recurso de cámara en mano, en su mayoría en un enfoque subjetivo siendo Jonathan quien observa a través de ella. La música y los sonidos toman un papel relevante también al complementar la voz de Jonathan en sus diferentes etapas de vida $(11,20$ y 31 años) dialogando con la cámara de video y enfatizando de muchas maneras, el amor por su madre, fin último de la realización de este trabajo documental.

\section{Marcela Zamora: El yo pregunta desde el dolor... en proceso de restauración individual y a su vez, restauración colectiva}

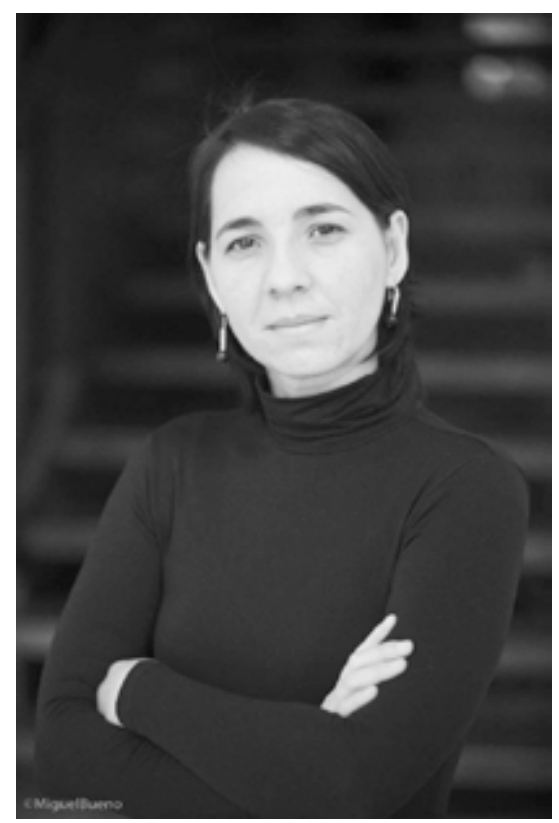

Figura 5. Marcela Zamora.

Marcela me expresa que "un documental siempre es sobre una motivación personal por el nivel de implicación que requiere" (M. Zamora, comunicación personal en entrevista conjunta con el Crítico de Cine Cedric Lepine, 16 de Diciembre de 2016). 
En la labor de encontrar la identidad de país, Zamora se ha embarcado en buscar los profundos rostros protagonistas de esa identidad. Rostros de país, que pueden ser tan metafóricos como el lado positivo y esperanzador en rincones negativos, como la muerte y la violencia, en una de las regiones que más "sangra" en Centro América (San Salvador). Con el documental "Comandos", discursa sobre la labor de personas que, en esquinas oscuras llenas de violencia, realizan actos heroicos de rescate. "María en tierra de nadie" encuentra esos rostros silenciados, incluso por los medios de comunicación, y prioriza la problemática de la migración vista a través de la voz femenina. El rostro más humano y lleno de sensibilidad, lo encontramos en "El cuarto de los huesos" aún siempre en el tema de la muerte, los desaparecidos y la brutal violencia por las pandillas en El Salvador.

Y entre una más extensa filmografía nos encontramos con su documental más personal: "Los Ofendidos". Film que nos permite abrir un espacio de conversación en la temática de la búsqueda de la identidad, tanto individual como grupal. En este sentido, Marcela Zamora nos da la oportunidad de explorar las posibilidades de re significación del yo en un campo individual que, a su vez, se traspasa a un colectivo que toma cuerpo como país (El Salvador) o, probablemente alcance linderos de subcontinente (Latinoamérica).

El documental como una búsqueda sobre el pasado, mantiene una narración contada directamente en primera persona. Explora y construye memoria, la misma Marcela Zamora lo afirma cuando reflexiona que, se "construía como ser humano y como hija, a la vez que construía (este) documental" dando voz a un sector muy sensible de la población salvadoreña.

El francés Cedric Lepine, hace notar que esta exploración como hija, es parte también de un duelo por la muerte reciente de su madre, pero al mismo tiempo es un duelo también como país que, después de muchos años, no ha sanado la enorme herida dejada por la guerra. Y Marcela lo admite... que durante la realización de este documental, pudo sentir claramente esa aseveración de tener un duelo personal con relación a su madre y un duelo eterno como país. Este duelo personal, es pues el detonante para la exploración de la figura de su padre, protagonista indiscutible de "Los ofendidos".

En concreto, es muy significativo que, esta circunstancia que genera la motivación principal para desarrollar esta búsqueda del yo en forma de documental es la llegada a manos de la directora a sus 33 años del "libro amarillo" que contiene rostros de personas torturadas en uno de los momentos más duros de la historia salvadoreña. En este libro, Marcela encuentra para su gran sorpresa, la fotografía de su padre, develando aristas de una historia familiar que nunca se le ha contado; y por ello, en la que ella como hija, jamás ha indagado. Este hecho tiene una enorme dimensión para ilustrar esta dicotomía del "yo proyectado", en este caso la persona de Marcela Zamora y, en un sentido extendido, en el Salvador como país. Por un lado, una ruptura generacional, que sufre una desconexión de información sobre los horrores ocurridos en la guerra, que es amenazada con nunca poder cerrar ese círculo de dolor al ser borrado por la nefasta acción del olvido. En el momento en que Marcela tiene ese libro en la mano, se da cuenta que se está haciendo tarde para poder dialogar con quienes realmente saben qué ocurrió en esos años de tortura, el darse cuenta que una de sus fuentes primarias (su madre) ya no está para responder con la verdad sobre los hechos, urge a Marcela acercarse más, desde una perspectiva emocional, a su padre (Rubén Zamora), quien forma parte de un extenso grupo de personas que todavía pueden dar testimonio de esa verdad y que, probablemente, por buscar paz y tranquilidad para ella y toda su generación, no lo suelen comentar.

Entrando en el análisis fílmico del documental, uno de los recursos conceptuales y a la vez técnicos efectivos en el trabajo de Zamora, es el manejo de varias voces para conducir la narración. Principalmente la película se apoya en las voces de protagonistas (incluyendo a la misma directora), que plantean puntos de vista de sus circunstancias durante ese terrorífico momento y el tiempo inmediatamente posterior al mismo. Estos puntos de vista, gracias al nivel ético de la directora, provienen de los dos lados más opuestos del horror: las víctimas como Rubén Zamora, Juan Romagoza, Miguel Ángel Rogel y Neris González pasando por la perspectiva de los responsables de investigar a fondo esta verdad como el Secretario de Defensa David Munguia Payes y, por el otro lado, el extremo del horror en uno de los torturadores (lógicamente anónimo).

Los espacios donde se mueve la narración se convierten en otra de las voces protagonistas del documental. Algunos son el reflejo del horror extremo sufrido en esos años (cubículos que sirvieron de espacios de tortura) y también del horror del paso del tiempo por amenaza del olvido. Otros son los espacios familiares domésticos, que se contraponen a ese reflejo del miedo. Una de las secuencias más duras del documental es, como espectadores, acompañar a Neris González a reconocer esos espacios de tortura y reencontrarse con el horror, vemos el impacto lógico de dolor que le produce, pues el proceso de sanación, no ha sido cerrado.

Uno de los puntos importantes del documental es que las generaciones presentes están conociendo la historia del país a través de pronunciamientos oficiales sesgados, puesto que la voz de los verdaderos ofendidos no está teniendo los ecos necesarios para lograr la sanación. En esto, finalmente tenemos la voz de la directora, que no solo es evidente en el lenguaje cinematográfico fluido y maduro que utiliza, sino también su presencia física y su voz propia que cuestiona, y nos cuestiona, el porqué nuestras generaciones no preguntamos sobre nuestro pasado más sensible, la directora propone que puede ser "talvez por pena o tal vez por miedo". Zamora también reflexiona que debido a esta falta de memoria y falta de cuestionamiento sobre la profundidad de los hechos, esta historia de horror se está repitiendo en nuestros países ahora por otra motivación 
que involucra el crimen organizado y otras razones, pero que se están volviendo a desarrollar las estrategia de control a través del miedo, al igual que durante la guerra civil, la policía está volviendo a matar y a torturar.

De esta forma, el documental plantea el cierre de un círculo sensible en la vida familiar de la directora, y se plantea como un ejemplo que evidencia la necesidad urgente de indagar más profundamente la verdad, sobre el círculo tumultuoso de violaciones de los derechos humanos, producto de la guerra civil en El Salvador, que no ha podido llevarse a cabo y que lo necesita como catalizador para ejecutar una restauración nacional.

\section{Darwin Yaney Mendoza: El yo a la orilla del río}

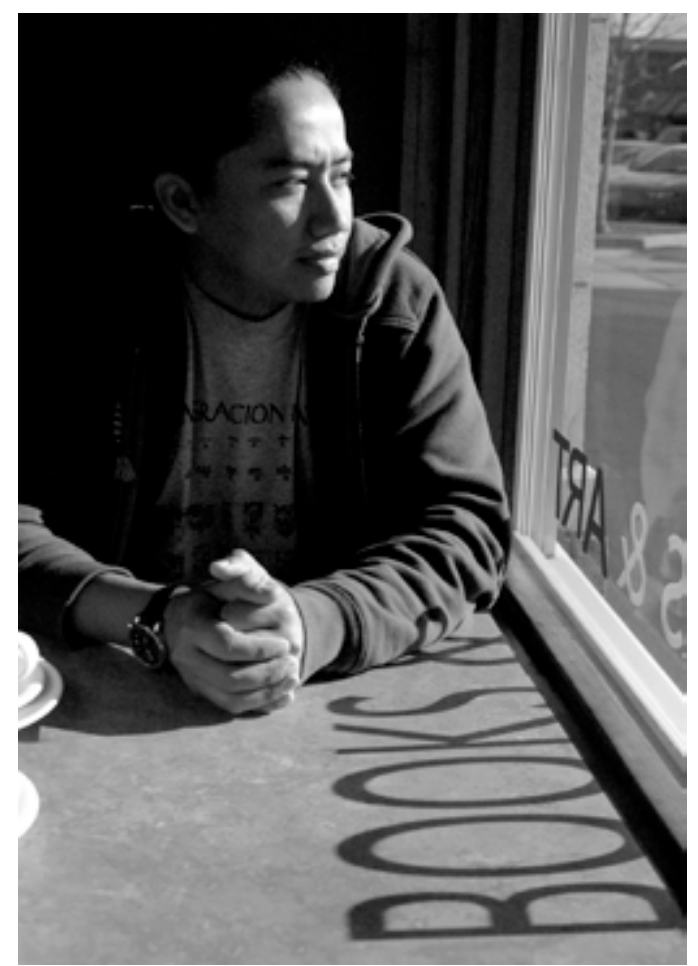

Figura 6. Darwin Yaney Mendoza.

Descubrir -en mi época adolescente- una historia personal tan crucial, máxime narrada por mi abuela a mí mismo y sobre mí mismo, casi siguiendo los lineamientos básicos de un guion literario; hoy por hoy, siento que tuvo que ser un detonante esencial para que mi yo, ese yo en proceso de formación, buscase, tiempo después, el definirse en una persona vinculada a la representación de historias a través del cine.
Esta historia de vida, nunca mejor dicho, que hoy denomino "La Orilla del Rio", tuvo que haber quedado guardada en el inconsciente, hasta que mi formación profesional como contador de historias sintiese la seguridad de poder resumir y estructurar el hilo conductual para que el espectador pudiera compartir conmigo ese momento de vida. La historia de Blanca y Ángel, y el cómo tuvieron que apostar a lo desconocido por una necesidad de creer, era una historia que siempre tenía (y probablemente tengo) pendiente de contar con los detalles suficientes que enriquecen ese acto de fe. "La Orilla del Rio," como pieza audiovisual, sometida a mi análisis desde un punto de vista psicológico, me arroja datos, sobre todo al cómo me vinculo con esa historia. Lo primero que sale a relucir, es la necesidad de distanciarme de mí mismo para poder imaginar los eventos en la historia desde una perspectiva exterior. Centrar mi atención narrativa y el ángulo de visión sobre la pareja de padres que emprenden un viaje motivados por la fé como último recurso al que aferrarse, es una decisión natural, puesto que en la mayor parte de la narración, el niño (yo) no está (no estoy). En la estructura del documental, la mención del yo está sólo al principio y al final.

Analizando el documental observo que he dividido mi presencia en tres maneras de representarme, al principio, muy sutilmente, mi imagen actual como guionista graficando la historia y dando la espalda al espectador. En el desarrollo de la narración, mi presencia es en dibujo -como parte del story board- y con mi voz en off re-contando los hechos para mí mismo. Al final, dirigiéndome directamente al espectador, en texto escrito cuando me pronuncio, acepto $y$ asimilo la historia como mía, develando que toda esta historia de un milagro transcurrió alrededor de mi persona.

El hecho de representar estos eventos a través del dibujo en sepia, dota de levedad a todo el cuento, y ello me indica que veo esta historia como una historia del alma, donde no es necesario sentir los hechos tan reales, sino en un plano más cerca de los linderos de la espiritualidad.

Otro dato importante, que resalta en la estructura narrativa, es la manera en que represento la llegada de la presencia del ángel Rafael a mi persona, haciéndolo incorporarse a la narración de manera paulatina, dando al espectador pistas del recuento de vida de este maravilloso personaje espiritual, que a la larga es quien me dota nuevamente de vida y me da nuevamente un yo, ahora evidentemente lleno de fe y con un sentir espiritual muy grande.

Concluyendo, el analizar cuáles han sido algunas de las estrategias que como cineastas se pueden utilizar para visualizar el Yo a través de las posibilidades del medio $y$, de esa forma repensarlo, me ayuda indudablemente a seguir indagando la obra de creadores e investigando caminos que, de alguna manera, nos lleven a seguir entendiendo esa necesidad de resignificar el Yo como punto de partida, con el objetivo de llegar a entender el núcleo base del comportamiento de nuestra sociedad. El cineasta con la complicidad activa del espectador puede, como hemos 
visto, desdoblar su perspectiva personal para observar de infinitas maneras su propio Yo; igualmente, puede distanciarse y ubicarlo con ayuda de otros frente a sí mismo y cuestionarlo, hasta compartir un sentimiento tan profundo como la liberación lograda por una contraparte. Compartiendo necesidades y modelos de conducta, identificamos otros individuos que, a manera de espejo, nos ayudan a entender nuestro Yo e incluso a ir creándolo vicariamente debido a la falta de independencia; y sin embargo por el contrario, nuestro Yo puede ser un referente de conducta para una identificación colectiva. En definitiva, creo que llegados a este punto es loable tener la posibilidad de poder plantearnos el Cine como herramienta que nos permita ubicarnos y escoger una efectiva posición con relación a visualizar y estudiar nuestra propia personalidad.

Confío que esta inquietud que les presento a través de esta breve primera incursión de vía de estudio: el Cine y la exploración del Yo, nos abra el compartir un espacio de diálogo que nos conduzca a una enriquecedora investigación sobre el "Yo" frente al cine, como aparato útil que, a manera de espejo, sin duda puede reflejarnos y mostrarnos detalles de nuestro "yo" y así entendernos -en el sentido más amplio del Ser- cada vez mejor.

\section{Bibliografía}

Couette, J., Winer, S. (Productores) y Couette, J. (Director). (2003). Tarnattion [documental]. EU.: Spring Media.

Danto, Arthur C. "Transfiguration of the common place" (1974). The Journal of Aesthetic and Art Critissism, 33(2), 139-148.

Deren, Maya. (1946). "An Anagram of Ideas on Art, Form and Film." New York: The Alicat Book Shop Press

Frampton, H. (Productor) y Frampton, H. (Director). (1971). Nostalgia. [documental]. E.U.

Gaitan, Nery Alexis. (2011). "El Delirio de Contar: Entrevistas a Narradores Hondureños." Tegucigalpa: Perseo Ed.

López Fernández, J. (Productor) y Zamora, M. (Directora). (2016). Los Ofendidos [documental]. El Salvador.: El Faro y Kino Glaz.

Mulvey, Laura. (1999). "Visual Pleasure and Narrative Cinema." En: Film Theory and Critisism: Introductory Readings. (833-844) Eds. Leo Braudy y Marshall Cohen. New York: Oxford UP.
Paul, Arthur. (2005). "Extreme Makeover: The Changing Face of Documentary." Cineaste, 30(3), 18.

Schütz, Alfred. (1993). "La Construcción Significativa del Mundo Social." Barcelona: Paidos.

\section{(c) (i) (으을}

Esta obra está bajo una licencia de Creative Commons Reconocimiento - NoComercial - CompartirIgual (by-nc-sa) 